Communication

\title{
A Systems Approach to Establishing an Advanced Manufacturing Innovation Institute
}

\author{
Gregory Harris *(D) and Lauren Caudle \\ Industrial \& Systems Engineering Department, Auburn University, Auburn, AL 36849, USA \\ * Correspondence: greg.harris@auburn.edu; Tel.: +1-334-844-1407
}

Received: 30 June 2019; Accepted: 13 August 2019; Published: 16 August 2019

\begin{abstract}
Systems engineering is a methodology where an interdisciplinary approach is applied, using systems thinking, to the development of a system of interest. The systems engineering discipline has emerged as an effective way to guide the engineering of complex systems, but has been applied most readily in the realm of cyber physical systems. In some circles of the Federal Government, the mention of systems engineering processes immediately leads people to think of a long, inefficient effort due to an often applied bureaucratic approach, where the focus is on documentation rather than the development of the system of interest, which comes from a view that the product of the systems engineering effort is the document, not the system itself. In this paper, the authors describe the application of systems thinking and the systems engineering process to the design and creation of an Advanced Manufacturing Innovation Institute (MII, part of the National Network for Manufacturing Innovation) established under Department of Defense (DoD) authority for the Office of the President, that was swift, efficient, and implemented without formality.
\end{abstract}

Keywords: digital manufacturing; National Network for Manufacturing Innovation; advanced manufacturing institutes; organizational design; systems thinking; systems engineering process

\section{Introduction}

In the 20th century, the U.S. was the world leader in manufacturing and innovation. However, as the century ended and companies sought quick profits by off-shoring and out-sourcing, the U.S. began to lose its ability to innovate. This trend progressed to the point that in 2009, The Economist wrote an article announcing the death of manufacturing in the U.S. [1]. By 2102, a re-emphasis on advanced manufacturing, digital capabilities and innovation resulted in that same publication announcing the renaissance of manufacturing, and by extension, innovation [2] (Figure 1).

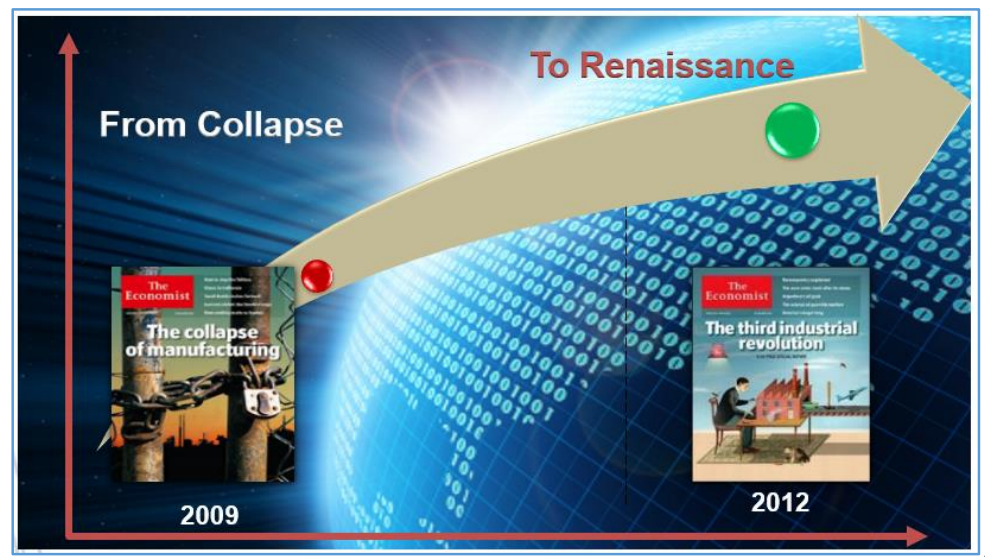

Figure 1. Dramatic change in manufacturing outlook. 
In 2012, at the direction of President Obama, the Administration launched an initiative focused on strengthening the innovation, performance, competitiveness, and job-creating power of U.S. manufacturing. This initiative, called the National Network for Manufacturing Innovation (NMII, now branded as Manufacturing USA, Figure 2), was to establish a network of regionally focused advanced manufacturing innovation institutes as public-private partnerships (PPP), while collectively forming a sustainable national manufacturing innovation engine to develop and scale critical manufacturing technologies [3].

In the 2013 State of the Union address, President Obama outlined a plan to strengthen the middle class plus reignite America's engine of economic growth through advanced manufacturing [4]. This initiative required a combination of efforts to revive innovation, encourage commercialization and create a skilled and engaged workforce. Restoring the U.S. as a magnet for advanced manufacturing, and equipping Americans with the requisite skills to perform these jobs, would ensure a robust and growing middle class.

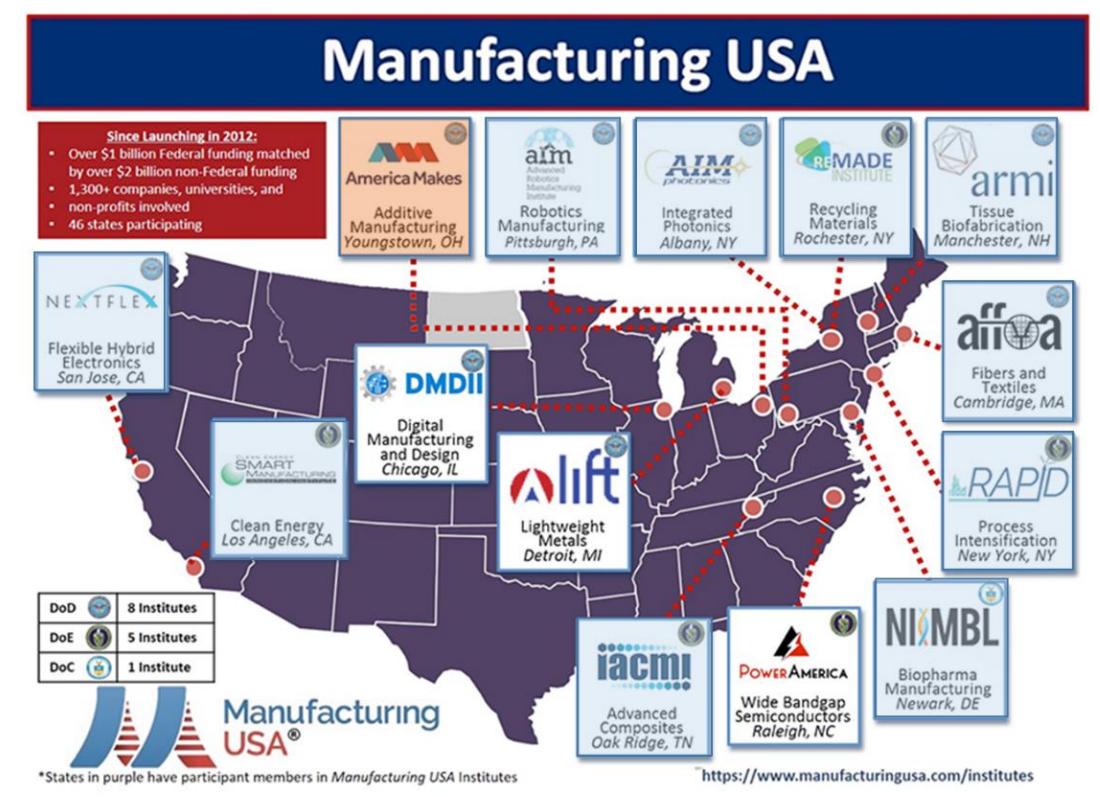

Figure 2. MII network: Orange-Pilot Institute; Blue-MIIs established later; White - DMDII, LIFT, and Power America were all being developed at the same time (2013-2014) [5].

The President's plan to revitalize the manufacturing sector included "partnering with businesses and communities to invest in American-made technologies and American workers through a network of Manufacturing Innovation Institutes (MIIs)" [4]. These institutes would have regional emphasis, but a national mission, bridging the gap between applied research and commercialization through a PPP of industry, academic institutions, and Federal agencies. The institutes would focus on key technology areas that encourage investment and production in the U.S. The MIIs would provide an opportunity for education and training of students and workers, plus provide shared assets to help companies gain access to cutting-edge capabilities and equipment to design, test, and pilot new products and manufacturing processes [6].

The President initially called upon the Department of Defense (DoD) to initiate the effort, and using a multi-agency, whole-of-government approach, the DoD established the NNMI's Pilot Institute in August 2012, now branded as "America Makes", which focuses on advancing additive manufacturing technologies [7]. After the stand-up of the pilot MII, and building upon its success, the Administration requested additional topics to be considered for new MIIs. The President directed the DoD, Department of Energy (DoE), and Department of Commerce (DoC) to establish three additional institutes in Fiscal Year 2014 (Figure 2, white boxes). The request for topics went to the DoD, DoE, and DoC. The U.S. 
Army accepted the challenge for one of the institutes and committed to standing up the Digital Manufacturing and Design Innovation Institute (DMDII).

This paper describes the approach used to design, develop and implement the DMDII initiative. In Section 2, the development of the topic, understanding the problem space, and how systems thinking and the systems engineering process were employed, are described. Section 3 presents the decomposition of the problem through stakeholder identification and elicitation, development of the system needs and the resulting system requirements. Section 4 describes the requirements analysis and architecture analysis approach to the proposed alternatives. Finally, Section 5 presents some conclusions from the authors.

\section{Materials and Methods-The Environment}

Acting upon the request for new advanced manufacturing topics from the Administration, the DoD asked the Joint Defense Manufacturing Technology Panel (JDMTP) to provide ideas for new institutes. The JDMTP consists of a representative from the Army, Navy, Air Force, Defense Logistics Agency, Missile Defense Agency, and Office of the Secretary of Defense. Each of the representatives manages a Manufacturing Technology (ManTech) program. The focus of the JDMTP is to avoid redundancy in initiatives, develop joint requirements, and jointly plan and develop strategies. The work of the JDMTP is conducted by technology Subpanels. There are four Subpanels consisting of members from each of the services and agencies, along with ex-officio members from industry and academia. The Subpanels meet to review project portfolios, identify collaboration opportunities, and provide information regarding future investment areas. The chairs of each Subpanel meet to coordinate projects crossing subpanel boundaries and improve processes to increase efficiency and effectiveness in achieving the ManTech mission [8].

This group of Subpanel Chairs were tasked with the development of new institute topics. One of the authors, Harris, was serving as the Chair of the Advanced Manufacturing Enterprise Subpanel of the JDMTP [9] and was one of those asked to submit ideas to the Administration for consideration. Dr. Harris and Mr. Paul Huang, who was with the Army Research Laboratory and now the Office of Naval Research, submitted an idea for an institute based on Digital Manufacturing and Design. The idea was founded on a belief that the next significant opportunity for productivity improvement, the digitalization of manufacturing and the supply chain, and establishing true Model-Based Enterprises, is critical to the U.S. reestablishing leadership in advanced manufacturing

\subsection{Why Digital Manufacturing and Design?}

Manufacturing is at the tipping point of an explosive rise in capabilities due to the merging of the digital and physical worlds. The growth of computing capability, software complexity and networking is ushering in an era that will bring unprecedented capability through the combination of connected minds and machines. Materials science, supply chain, industrial and systems engineering, machine automation and data science, which are the foundation of manufacturing, are undergoing a renaissance as the speed and availability of computing power, prolific data sets, automated workflows and collaborative thinking reshape how manufacturing operations are considered, designed and implemented.

The persistent growth and reach of this digital system will enable future designers, modelers, engineers, simulators and operators to take advantage of significantly higher levels of creativity and knowledge as barriers evaporate. Advanced tools and knowledge of the trade will enable crowdsourcing, collaboration and high-performance computing technologies to democratize the manufacturing process and give manufacturers the ability to compete on a global basis where speed, innovation and productivity are required to win.

In this not so futuristic manufacturing world, the 'Digital Thread' enables designer, analyst, manufacturer, and maintainer collaboration. Manufacturing modeling and simulation tools allow faster time to market and efficient production of desired systems. Multiple designs, prototypes, and test iterations typically required for product or process qualification are minimized. High-performance 
computing is utilized to develop physics-based models of performance to include manufacturing requirements early in the design process. Production is effective and efficient whether the product characteristics of demand are unique "one-off" products, mass produced, or a combination, such as mass customization. The workforce is capable and confident in the use of technology on the shop floor to minimize delays and improve flow. The development and integration of smart sensors, controls, metrology, analysis, decision and communication software tools for self-aware manufacturing provides data to enhance continuous improvement and sustainability. Plug and play functionality allows equipment to utilize manufacturing knowledge and enables better decision-making while planning and processing components.

This future vision is complex and beyond the risk industry is willing to take on its own, with companies opting for out-sourcing to lower costs in lieu of technology and infrastructure investments. Therefore, this topic was one in which the development of a PPP under the NNMI could propel American industry back to the forefront of advanced manufacturing. The purpose of DMDII would be to integrate information technology, computer simulation, 3D Models, Model-Based Enterprise, advanced materials, and analytics to bring a revolution in development and application of manufacturing intelligence to every phase of the product life cycle. A national institute would offset the risk to industry in adopting new technologies and promote competitiveness [10]. To succeed in this new digital environment and lead the cause for the implementation of advanced digital technologies in manufacturing would require the creation of an organization capable of working with industry, academia and government to develop and promote the technology needed to overcome the current gaps in this Digital Thread.

\subsection{Understanding the Problem Space}

The PPP created with this initiative is a complex socio-technical system working for and with U.S. manufacturing enterprises who face even more challenges of complexity with what can be designed, built, sustained, and analyzed to meet customer requirements. Product and process complexity is constantly increasing while the lead time to develop these products from design to the customer is decreasing (Figure 3) [11]. Increased complexity, in both organizations and products, creates difficulty in understanding the relationships among subsystems, can increase unproductive behaviors due to tunnel vision into specific system components and negatively affect communications [12]. The factory of the future or agile organization is within reach, with prospects of automation, affordability, and transformation of our manufacturing workforce [10].

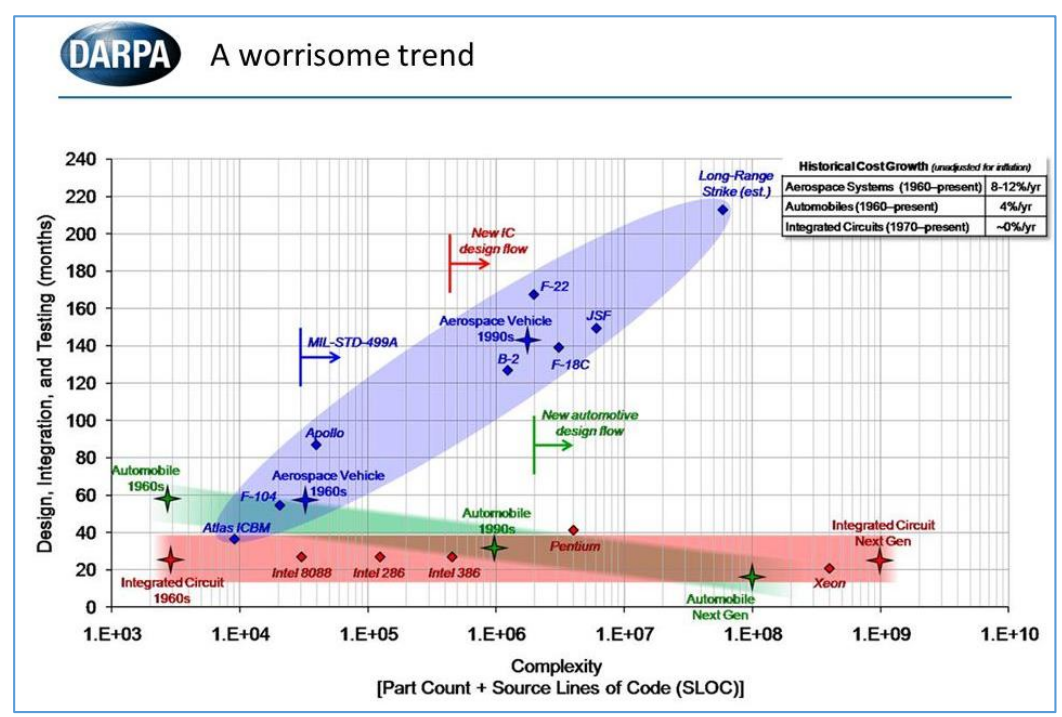

Figure 3. Growing Complexity [13]. 
Increased agility is an approach that can be used to deal with increasing levels of complexity [14-17]. An agile organization is characterized by the ability to move quickly and easily, with grace, and implies responsiveness. Agility and responsiveness provide the capability to quickly move from customer wants and needs to actionable system requirements used to develop innovative solutions [18]. In the agile and responsive organization, the flow of information and product are not impaired or constricted throughout the realization process. To achieve agility and responsiveness in manufacturing requires advanced manufacturing concepts. Advanced manufacturing employs innovative, ground-breaking technologies that provide significant improvement in the capability to achieve the customers' desired results in product and system realization. To this end, the future in manufacturing and design is a networked and interoperable system with agile and robust manufacturing strategies and integrated capabilities that dramatically reduce the cost and time of producing complex systems and parts. The requirements process is streamlined and efficient.

To assist industry in achieving this level of capability, the DMDII would need to have the capability to provide thought leadership, solve technology-related problems and provide guidance on industrial policy. An organization such as this is truly complex. An extremely aggressive timeline for the solicitation and creation of this organization imposed by the Administration increased the complexity of the initiative. Studies of complex system projects indicate that there is a correlation between investment in systems engineering and a reduction in program cost and schedule overruns [19]. If systems thinking is beneficial to the understanding and solving of complex problems and systems engineering can improve project performance on the development of complex systems, then it is reasonable to assume that the application of synergistic systems thinking and systems engineering to the creation of a new organization focused on the development, maturation and commercialization of advanced manufacturing technologies would bring about a successful result [20].

\subsection{A Systems Approach}

Applying systems thinking to this complex problem seemed to be a reasonable approach, but systems thinking has different meanings to people based upon their belief systems, context, and knowledge. Systems thinking obliges that a holistic view of the system is taken that involves both spatial and temporal elements of the system. Systems thinking is a powerful approach to solving complex problems that may not be solvable using scientific-method-based approaches that have been the norm for the past two centuries [21,22].

The basis of systems thinking is that the world does not consist of separate, unrelated forces, but rather there is a connection between entities that simply need to be uncovered and discovered [23]. Significant components of systems thinking are a focus on the whole process, consideration of the issues, evaluating the factors and influences, and the inclusion of patterns, relationships and common understanding in the review and analysis [22]. Systems thinking is an all-inclusive approach that focuses on understanding the interconnections of the system components [20]. Senge states that systems thinking is a conceptual framework and body of knowledge that provides a rigorous way of integrating people, purpose, process, and performance [23]. Systems thinking makes the complex understandable, provides opportunity to maximize outcomes, aligns the team, and helps manage uncertainty and risk.

An organization is a consciously coordinated social entity with an identifiable boundary that is working to achieve a common goal [24]. The vitality and productivity of an organization depends largely on its structure and behaviors [25]. Design of the organization is concerned with what the organization should be, which is achieved through a shared vision and skills applied to reveal a picture of the future that achieves adoption by the participants $[23,25]$. Researchers have investigated the application and success of systems thinking as an organizing principle in the development of organizational strategies [26]. There are many organizational theories, yet general principles to organizational design that can be applied at all times are not well known, in fact, most theoretical 
findings in organizational design are informal and vague [25]. Each application of systems thinking is unique.

\subsection{Systems Engineering}

One method of applying systems thinking is the use of the systems engineering process for understanding a problem and developing appropriate solutions. Systems engineering is a useful development approach and an effective way to guide the engineering of complex systems, but to date, has been applied most often in the realm of cyber physical systems. Systems engineering processes have not been applied as often, or as thoroughly, in the development of organizations. Senge pointed out, almost three decades ago, that organizations are complex systems, actually systems of systems [23]. According to the International Council on Systems Engineering (INCOSE) a System of Systems (SoS) is, "A system of interest whose elements are managerially and/or operationally independent systems. These interoperating systems produce results unachievable by the individual systems alone" [27]. This definition does not only apply to cyber physical systems, but can easily be applied to organizations. Whether a cyber-physical system or an organization is the focus, systems engineering is the methodical, interdisciplinary approach and means to enable the development of a successful system [20,28]. Systems engineering involves using appropriate technologies and management principles to address the business and the technical needs of stakeholders with the goal of providing a resulting system that meets the user's needs $[29,30]$. Thus, systems engineering is a problem-solving approach that applies systems thinking to complex problems, such as the creation of an advanced manufacturing institute.

However, in some circles of the Federal Government, the mention of employing a systems engineering process immediately leads people to think of a long, drawn out, and inefficient effort due to an often applied bureaucratic approach where the focus is on documentation of the system rather than the development of the system. In developing the approach to the complex DMDII initiative, the Program Manager (PM) determined that to achieve success in an environment of constrained resources and extremely aggressive timeline, as was being defined by the Administration, it was essential to utilize a systems approach. Though the decision was made to utilize a systems engineering process, the PM decided not to state this publicly to negate any biases toward using the approach. In this way, the development and solicitation team would focus on the tasks and design, not documentation and checklists.

In the following sections, the application of systems thinking and the systems engineering problem solving approach is described.

\section{Results-Applying the Systems Engineering Process}

The Vee Model (Figure 4) is often used to visualize the focus of the systems engineering process during development [30]. The left side of the Vee illustrates the decomposition of the system into the manageable components with a focus on understanding the purpose of the system, defining the problem, identifying stakeholders and their needs, identifying and considering constraints, performing tradeoffs, and the creation of well-developed system requirements.

The bottom of the Vee begins the creation of the system of interest and the implementation of the system from components to the completed system. The requirements analysis process leads with the development of architectures and concepts. Analysis of alternatives is undertaken to determine the design that best meets the requirements.

The right side of the Vee has a focus on implementation, verification, and validation of the system solution with clear traceability to the system requirements developed earlier. After design selection, the focus is on final design of components and ensuring that the designs are traceable directly to the established requirements, at which point, we launch the system through implementation. This is the methodology used in the development of the DMDII. 


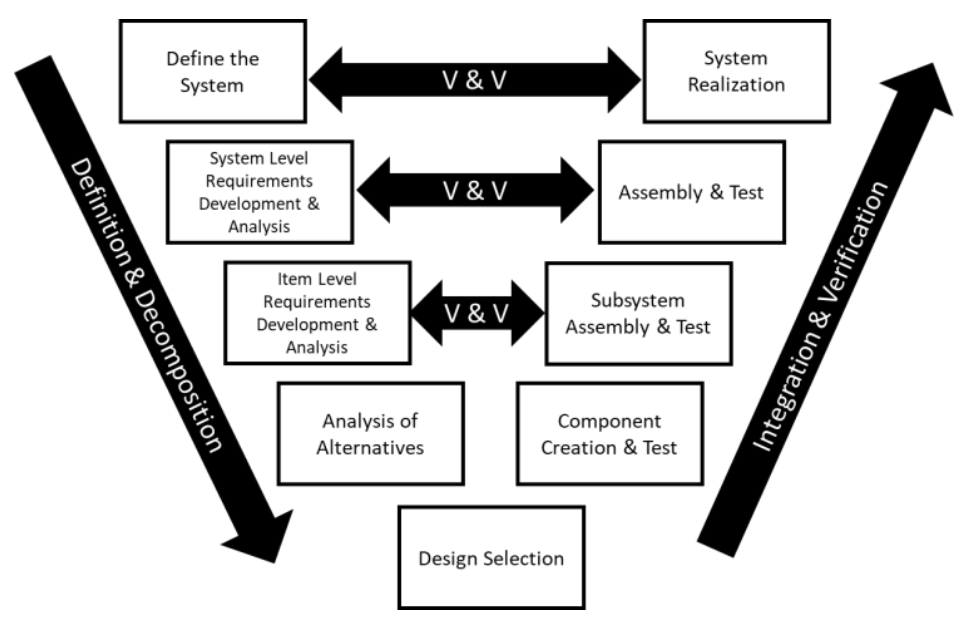

Figure 4. Vee model [30].

Part of the issue with use of systems engineering in the government is the formality (or perceived formality) of the process and the focus on the deliverables, such as the System Requirements Specification. The problem that the PM for the DMDII initiative had to overcome, knowing that the timeline would not allow for a formal establishment of a systems engineering initiative, was how to efficiently use the systems engineering process quickly, and within the bounds and capabilities of the Federal Government solicitation process. The following sections describe how several of the solicitation tools, such as the Request for Information (RFI) process was used for stakeholder and needs identification, and a Broad Agency Announcement (BAA) was a proxy for a system requirements specification.

\subsection{Defining the Problem}

The key to any successful system development activity is the thorough understanding of the problem being addressed (Figure 4) [31]. The problem statement for DMDII was created through a White Paper written for the topic selection process for DoD leadership and the White House. In this White Paper, the need, environment, and issues were described and the case was made for a government initiative to engage with industry and academia to overcome the issues that are keeping industry and government from fully implementing digital technologies in manufacturing. Specifically, the White Paper noted that the Government has led several independent initiatives addressing technologies both on and above the factory floor with the goal of maximizing the use of digital data across the life cycle of products, often termed the Digital Thread. The establishment of an institute with this digital manufacturing focus would be a natural extension of the separate, stand alone, projects previously undertaken.

The Digital Thread captures information generated throughout the life cycle of the product or system and allows for the consumption and addition of information by the entity needing it at the appropriate time. Early consideration of manufacturability, during both the development of the science and technology, and the design and acquisition phases, is essential to dealing with complexity. Government and industry both have recognized the need to integrate physics-based characteristics into models that enable the simultaneous consideration of the physical configuration, computational elements, and predictable system behaviors. The intended results are reduced lead time, decreasing tooling cost, and increased fidelity in manufactured parts for quality control of the final product.

The need to fully define the problem for the newly proposed institute was beyond the scope of the government team; therefore, an RFI was developed to solicit input from experts in industry and academia [32]. Information was requested to better define the current limitations in the domain of digital manufacturing and assist in defining and maturing the technologies necessary to create the enabling systems to provide a step function improvement to U.S. Manufacturing. The Government 
team identified four core technology areas of interest for the institute: Intelligent Machines, Advanced Analysis, Advanced Manufacturing Enterprise, and Cyber-Physical Security. Responders to the RFI were encouraged to submit ideas in the original four topics or other technology areas they deemed important to the implementation and growth of digital manufacturing and design. Based upon the input received, the technology areas were reduced to three, Intelligent Machines, Advanced Analysis, Advanced Manufacturing Enterprise. Cyber Security was not included in the DMDII technology areas as the stakeholders indicated that this topic should become an institute of its own.

Along with the technology areas, the RFI sought to evaluate potential composition and organizational models under which an institute may operate. Additionally, there was interest from the government on identifying potential enabling products that would emerge from the research and implementation of institute initiatives. Forty-five responses to the RFI were received. The input from the RFI responses was analyzed and used to inform the requirements for the creation of the institute. There were 24 reviewers of the RFI responses from 12 Federal Agencies and Departments.

\subsection{Stakeholders}

The identification of stakeholders and the elicitation of their needs related to the system of interest are critical activities in the system development phase (Figure 4) [19]. The RFI not only served the purpose of helping to define the needs for the DMDII, it served a second purpose of assisting in the identification of previously overlooked stakeholders. In a PPP, the stakeholders can be numerous and diverse. Initially, the stakeholders were grouped into the three categories of Industry, Academia and Government. Although the Government is often considered the Public participant in a PPP, the actual General Public or Community can also be a significant stakeholder.

The Industry stakeholders include Original Equipment Manufacturers (OEMs) and Prime Contractors, along with the Small and Medium Manufacturers (SMMs) that make up most of the industrial supply chain. The Academic group includes the Universities and Colleges that are training the engineers of the future and conducting research in the realm of Digital Manufacturing and Design. The Academic group also includes the Community Colleges and Technical Schools that provide the training and skilled workforce needed by Industry. The Government group of stakeholders includes the Federal Government Departments and Agencies that not only have an interest in the development of Digital Manufacturing and Design capabilities but also provide significant resources to the endeavor. Government can also include the Local and State entities with a vested interest in the success of the PPP.

Within the Federal Government, there were many stakeholders, all with needs to be incorporated in the system requirements. The White House Office of Science and Technology Policy staff were deeply involved in every aspect of establishing the institute. The DoE and DoC were also responding to the President's initiative, similar to the DoD, which included participation from each branch of the Services along with the Defense Logistics Agency. Other Federal Government organizations engaged with the effort included the Department of Homeland Security with the Coast Guard, the National Science Foundation, the National Institute for Standards and Technology (NIST), and the Defense Advanced Research Projects Agency (DARPA), and the National Laboratories of the DoE.

\subsection{System Needs}

The needs elicitation process, part of the decomposition of the system into components (Figure 4), established the elements of the larger DMDII system. The Federal investment and the cost share from non-public partners in the NNMI would serve to create a manufacturing research infrastructure for U.S. industry and academia to solve industry-relevant problems. The NNMI was to consist of linked MIIs with common goals, but unique concentrations. In an MII, industry, academia, and government partners leverage existing resources, collaborate, and co-invest to nurture manufacturing innovation and accelerate commercialization [3]. As sustainable manufacturing innovation hubs MIIs create, showcase, and deploy new capabilities, new products, and new processes that can impact commercial production. They build workforce skills at all levels and enhance manufacturing capabilities in 
companies large and small. Institutes pull together the best talents and capabilities from all the partners to build the proving grounds where innovations flourish and to help advance American domestic manufacturing [3].

Because the challenges associated with manufacturing are multi-faceted within the NNMI model, each MII has its own distinct manufacturing topic or technology focus. In their individual focus areas, institutes act to anchor a region's innovation infrastructure and conduct research and demonstration projects [3].

\subsection{Constraints}

The constraints on the DMDII system were identified during the development of requirements and the flow down of those requirements to the system elements (Figure 4). A primary constraining requirement from the Administration was to find a way to move quickly through the solicitation process. The solicitation process for institutes was pioneered by America Makes using a Cooperative Agreement (CA) as the award instrument and a BAA with a one-step proposal process. The timeline for America Makes was originally a 6-month effort. The actual time from the BAA to award was approximately 8 months. This was determined to be unsatisfactory due to the lack of time it allowed the solicitation team to evaluate inputs and respond to improve the offering or re-evaluate opportunities. It was decided that the DMDII solicitation would be a two-step process that would consist of an initial Concept Paper detailing the basics of the conceptual architecture that would be reviewed for selection to a subset of responses that best met the requirements [10]. Selected Concept Paper teams were asked to prepare a Full Proposal detailing their particular approach to satisfying the requirements as stated in the BAA. The initial schedule for DMDII was set for 9 months, but after evaluating the pilot effort, it was deemed that a 12-month schedule would be used.

A second constraint was that, due to the lack of budget movement in Congress, the institutes must be funded using existing funds and authorities. Additionally, the solicitation team had to find ways to make the effort a 'whole of government' initiative which meant including as many Federal agencies and departments as possible. The constraints imposed by the Administration on the DMDII program significantly increased the complexity of the effort.

\subsection{System Requirements}

System requirements were developed from the list of identified needs elicited from all stakeholders in the system development process (Figure 4). There were two main categories of requirements; (1) technical, and (2) organizational. Since there is no single organizational structure that will fit all situations [33], the requirements for the organizational component were left fairly wide open with the exception that the institute shall be led by a non-profit organization. These organizational requirements were then compiled into a BAA [10] to be issued for self-assembled proposal teams to develop their proposed architecture solutions for submission.

Technical requirements were performance-based rather than prescriptive so as to not hinder the creativity of solutions architected by the proposal teams. Since global competitiveness is driven by the speed at which products can enter the marketplace at a competitive price point, this institute's focus shall be on enterprise-wide utilization of the Digital Thread, enabling highly integrated manufacturing and design of complex products at reduced costs and time. Government and industry also needed a way to reduce the risk of adopting new technologies. The DMDII shall reduce that risk by providing a demonstration facility that integrates the next generation of manufacturing practices utilizing intelligent machines with advanced product development on the factory floor and advanced factory command, control and communications to demonstrate agile, flexible and reconfigurable operations. Rapid development and application of manufacturing intelligence to every phase of the product life cycle has the potential to fundamentally change how products are invented, manufactured, shipped, sold, and supported. It could be a key factor in keeping jobs in the U.S., by helping manufacturers become more competitive in the global marketplace. 
DMDII shall bring together the resources and developmental potential of the federal government, manufacturers, software providers, component suppliers, product designers, academia, state and local governments, and other key stakeholders. This PPP shall foster agile manufacturing advances that provide support to both government and commercial needs, developing market-focused manufacturing advances supporting product and system performance, affordability, and ultimately, increased market demand. These dynamics suggest strongly the need to instill within this collaborative environment an integrated approach that applies systems engineering principles to foster advanced manufacturing innovations that help to optimize component and system designs and accelerate time to market. Focused collaboration and leveraging the resources of the institute shall drive innovations across the TRL/MRL 4-7 to reduce risks. This will help transition these critical new manufacturing capabilities into the U.S. industrial landscape to enable production scale-up and commercialization. To provide a "step function" improvement in the manufacturing capabilities of the U.S, the focus of the institute leadership shall be on the development and guidance of the DMDII technology plan, the development and execution of the project calls, and the selection and monitoring of institute-awarded technology maturation projects.

\section{Discussion-Analysis}

Due to the shutdown of the government during the DMDII solicitation process in 2013, the originally planned 12-month schedule grew to a 14-month process. The fact that the shutdown took place during a holiday period placed additional stresses on the team and the analysis of the proposals.

\subsection{Requirements Analysis}

The PM believed that it was not in the best interest of the development of DMDII to establish the system requirements based upon a voting outcome of the solicitation team which could bring out individual biases as positions to be defended. Rather, the team used a consensus approach to determine the items of importance to include as stakeholder needs. As the project moved into the requirements development and analysis phases, no votes were taken, instead consensus building was used to achieve the desired outcomes. Alternate conceptual designs were developed by proposal teams, in the form of Concepts Papers, for evaluation against the requirements documented in the BAA. A team of 28 Government Subject Matter Experts (SMEs) worked to evaluate thirteen Concept Papers submitted by prospective teams. The SME team chose five of the thirteen Concept Papers that best met the requirements to move to Full Proposal in the solicitation process. Once the full proposals were received, an analysis of how they achieved the requirements detailed in the BAA was undertaken.

\subsection{Analysis of Alternatives}

The DMDII purpose was to assume the role of convener, bringing together large and small businesses, academia, and federal and state agencies to accelerate innovation by investing in industrially relevant manufacturing technologies, typically through the analysis of industry needs and the establishment of a research project portfolio focused on the most relevant issues. The projects in the portfolio are performed initially for the benefit of the consortium, but available to the broader industrial base as the technologies are transitioned. Additionally, the DMDII is to serve as a technical center of excellence, providing infrastructure and capability to support manufacturing enterprises of all sizes and ensure that the U.S. manufacturing sector is dynamic and robust.

The goal of DMDII is to increase the successful transition of innovative digital manufacturing and design technologies to industry and help to create a workforce capable of meeting industry needs. As such, the DMDII has a work force development component in each project in the portfolio. All functions of the DMDII are performed for the good of the U.S. Industrial base, both defense and commercial. It was against these purposes and goals that the SME team evaluated the proposals. The manner in which proposal teams achieved the system requirements drove trade studies for understanding which architecture had best met the intent of the requirements. 
The five invited full proposals presented five unique architectures. These architectures ranged from a loose confederation of existing non-profit centers to a new organization specifically developed for this initiative. Each Government reviewer was provided complete access to the responses from the proposal teams to evaluate on their own. The reviewers were also trained on the analysis approach and tool to be used, particularly on how to apply the rating scale (Figure 5) to the proposal team's response to the system requirements.

\begin{tabular}{|l|l|}
\hline \multicolumn{2}{|c|}{ RATINGS } \\
\hline \multicolumn{1}{|c|}{ ADJECTIVE } & \multicolumn{1}{c|}{ DEFINITION AND CRITERIA } \\
\hline Outstanding & $\begin{array}{l}\text { Proposal meets requirements and indicates an exceptional approach and understanding of the requirements. The proposal contains no significant } \\
\text { weaknesses. Strengths far outweigh any weaknesses. Risk of unsuccessful performance is very low. }\end{array}$ \\
\hline Good & $\begin{array}{l}\text { Proposal meets requirements and indicates a thorough approach and understanding of the requirements. Proposal contains strengths which outweigh any } \\
\text { weaknesses. Risk of unsuccessful performance is low. }\end{array}$ \\
\hline Acceptable & $\begin{array}{l}\text { Proposal meets requirements and indicates an adequate approach and understanding of the requirements. Weaknesses and strengths are offsetting or } \\
\text { will have little or no impact on contract performance. Risk of unsuccessful performance is moderate. }\end{array}$ \\
\hline Marginal & $\begin{array}{l}\text { Proposal does not clearly meet requirements and has not demonstrated an adequate approach and understanding of the requirements. The proposal has } \\
\text { one or more weaknesses which are not offset by strengths. Risk of unsuccessful performance is moderate to high. }\end{array}$ \\
\hline Unacceptable & $\begin{array}{l}\text { Proposal does not meet requirements and contains one or more deficiencies that would require extensive proposal rewrite resulting in high risk and is not } \\
\text { awardable. }\end{array}$ \\
\hline
\end{tabular}

Figure 5. Rating Categories for Concept Papers and Full Proposal.

A face-to-face meeting of all 28 SMEs participating in the proposal review team was held in which each proposal was presented by one member of the proposal review team assigned to that submission. All proposals were presented and discussed without a vote or ranking of the submission. The proposal review team reached a consensus on the proposal that was judged to best meet the documented requirements and achieve the purpose and goals of the program. It is important to note that although there were attempts by some stakeholders to influence the selection process, the SME evaluation team was completely insulated from those attempts and no pressure was exerted on the selection team to weigh any response more heavily than another.

The selection of a specific design by the evaluation team initiated the System realization activites (Figure 4). Verification and validation of design components started with the analysis of the five architectures and would continue through the implementation processes to create the desired DMDII organization.

\subsection{Architecture, Design \& Launch}

The submitted responses to the published requirements all contained a conceptual architecture for the institute. The final architectural design was achieved as a result of negotiations between the chosen submission, the U.S. Army Contracting Command, and the PM based upon the selected proposal. This process generated the integration, verification, and element realization for the final system solution (Figure 4). Once the final architecture was established, the contractual arrangements were determined.

An evaluation of contractual mechanisms was undertaken. The use of a Cooperative Agreement (CA) under 31 U.S.C. 6305 was determined to be an appropriate contracting vehicle. The principal purpose of the institute was to stimulate a public engagement but not to provide a direct benefit or deliverable to the Government, although it was expected that the Government would have substantial involvement. Based on the role of the Government in the institute, the use of a CA was approved. The negotiated CA contained all of the institute performance metrics tied to the system requirements for the period of performance of the agreement. The CA was signed on 21 February 2014 and DMDII came into existence. The announcement of the winning proposal was made on 25 February 2014 at the White House by President Obama (Figure 6). 


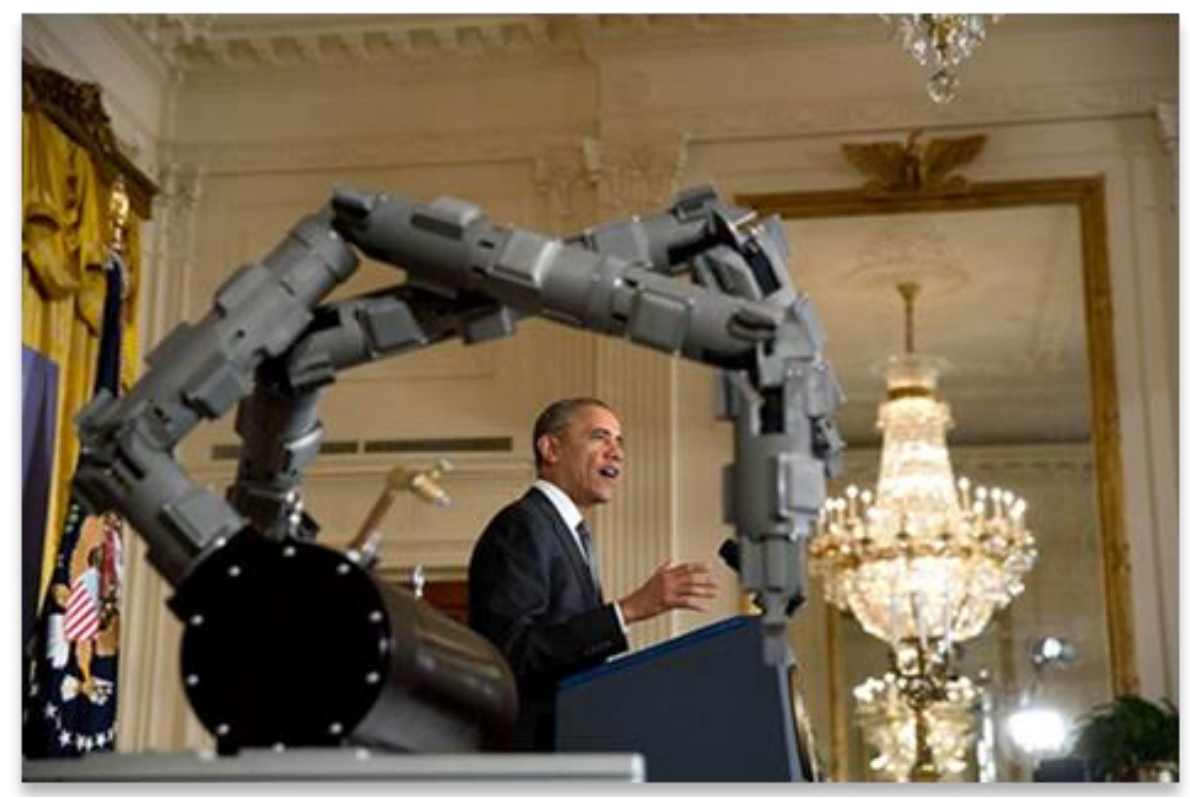

Figure 6. President's Announcement of the Digital Manufacturing and Design Innovation Institute (DMDII) at the White House, 25 February 2014.

\section{Conclusions}

Employing a systems engineering methodology with the perspective of systems thinking to develop the DMDII was the correct call. Under the unique circumstances of the program, the choice to not publicly state that a systems engineering process was being used worked out well. The inclusiveness of the approach, and the thoroughness of the requirements development and analysis process, made it possible to bring a large and diverse group of Government SMEs to reach concurrence on the selection of one proposal without taking a vote. Voting on an initiative such as this would have left the Government with a divided support base and could have caused significant damage to the fledgling organization. Using a systems engineering process and systems thinking to develop DMDII provided an excellent outcome in a time- and resource-constrained system development process. The fact that the PM was able to lead a large team through a systems engineering process in such a short time provides evidence that a systems approach can produce successful results and not be burdensome or lengthy.

\section{Post Script}

As of this writing, the DMDII has been in existence for more than five years and has awarded and managed more than 60 research projects with a total value of more than $\$ 95 \mathrm{M}$ in that time. The organization was rebranded after the initial five-year period of performance to $\mathrm{MxD}$ (manufacturing times digital). The institute has published an annual strategic investment plan identifying the industry areas of concern and produced a jobs taxonomy that describes the skill sets and positions needed in the new digital manufacturing and design environment. The institute has a digital capability center on site where projects can be tested and demonstrated in a safe and relevant environment. Additionally, MxD has established a cyber-security for manufacturing systems test bed and is expanding its scope to address this important aspect of digitally connected manufacturing.

Author Contributions: Conceptualization, G.H.; Methodology, G.H.; investigation, L.C..; resources, G.H.; writing-original draft preparation, G.H.; writing—review and editing, G.H. and L.C.; supervision, G.H.; project administration, G.H.

Funding: This research received no external funding

Conflicts of Interest: The authors declare no conflict of interest. 


\section{References}

1. The Collapse of Manufacturing. The Economist; Editorial; The Economist Group Limited: London, UK, 19 February 2009. Available online: https://www.economist.com/leaders/2009/02/19/the-collapseof-manufacturing (accessed on 29 June 2019).

2. The Third Industrial Revolution. The Economist; Editorial; The Economist Group Limited: London, UK, 12 August 2012. Available online: https://www.economist.com/leaders/2012/04/21/the-third-industrialrevolution (accessed on 29 June 2019).

3. National Network for Manufacturing Innovation: A Preliminary Design. Executive Office of the President, National Science and Technology Council, Advanced Manufacturing National Program Office. January 2013. Available online: https://www.manufacturingusa.com/reports/national-network-manufacturing-innovationpreliminary-design (accessed on 14 August 2019).

4. The White House. The President's Plan for A Strong Middle Class and A Strong America; The State of the Union Address; 12 February 2013. Available online: https://obamawhitehouse.archives.gov/sites/default/ files/uploads/sotu_2013_blueprint_embargo.pdf (accessed on 13 January 2019).

5. Manufacturing USA Map of Institutes, National Institute of Standards and Technology (NIST). Available online: https://defenseinnovationmarketplace.dtic.mil/map-manufacturing-usa/ (accessed on 27 June 2019).

6. The White House. President Obama Announces Two New Public-Private Manufacturing Innovation Institutes and Launches the First of Four New Manufacturing Innovation Institute Competitions; 25 February 2014.

7. America Makes. Available online: https://www.americamakes.us/ (accessed on 28 December 2018).

8. Joint Defense Manufacturing Technology Panel (JDMTP). Available online: https://www.dodmantech.com/ JDMTP/ (accessed on 27 June 2019).

9. Advanced Manufacturing Enterprise Subpanel of the JDMTP. Available online: https://www.dodmantech. com/JDMTP/AME (accessed on 27 June 2019).

10. Grants.gov; Broad Agency Announcement; Department of Defense; Department of the Army-Materiel Command. The Digital Manufacturing and Design Innovation (DMDI) Institute; (Check Archived Box). Available online: https://www.grants.gov/web/grants/search-grants.html?keywords=DMDI (accessed on 26 June 2019).

11. Kim, G.T.; Kim, Y.B. An expository note on an economic justification of investments in advanced manufacturing systems. Int. J. Adv. Manuf. Technol. 2005, 26, 934-941. [CrossRef]

12. Kessler, W.; McGinnis, L.; Bennett, N.; Makins, Q.; Nagao, D.; Bennett, N. Enterprise alignment and inertia risks during transformation. Inf. Knowl. Syst. Manag. 2012, 11, 151-168.

13. Eremenko, P. Adaptive Make: DARPA Manufacturing Portfolio Overview Briefing prepared for the MIT/OSTP Science of Digital Fabrication Workshop. 7 March 2013. Available online: https://slideplayer.com/slide/ 6152316/ (accessed on 29 June 2019).

14. Massie, J.G.; Davis, W.J. IBM toolkit for radical simplification of business processes. IBM J. Res. Dev. 2012, 56, 3:1-3:10. [CrossRef]

15. Joiner, B. Guide to Agile Leadership: Cover story. Ind. Manag. 2009, 51, 10-15.

16. Chiprianov, V.; Kermarrec, Y.; Rouvrais, S.; Simonin, J. Extending enterprise architecture modeling languages for domain specificity and collaboration: Application to telecommunication service design. Softw. Syst. Model. 2014, 13, 963-974. [CrossRef]

17. Kettunen, P.; Laanti, M. Future software organizations-Agile goals and roles. Eur. J. Futures Res. 2017, 5, 1-15. [CrossRef]

18. Harris, G.A.; Abernathy, D.; Whittenburg, R.; Holden, A.; Still, A. Issues in Implementing a Model Based Enterprise. In Proceedings of the 9th Model Based Enterprise Summit, NIST Headquarters, Gaithersburg, MD, USA, 2-5 April 2018. [CrossRef]

19. Honour, E. Understanding the Value of Systems Engineering. In Proceedings of the 14th Annual INCOSE International Symposium, Toulouse, France, 20-24 June 2004; Volume 14. [CrossRef]

20. Monat, J.; Gannon, T. Applying Systems Thinking to Engineering and Design. Systems 2018, 6, 34. [CrossRef]

21. Monat, J.; Gannon, T. What is systems thinking? A review of selected literature plus recommendations. Am. J. Syst. Sci. 2015, 4, 11-26. [CrossRef]

22. Kossiakoff, A.; Sweet, W.; Seymour, S.; Biemer, S. Systems Engineering: Principles and Practice, 2nd ed.; John Wiley \& Sons: Hoboken, NJ, USA, 2011; ISBN 978-0-470-40548-2. 
23. Senge, P.M. The Fifth Discipline; Doubleday: New York, NY, USA, 2006.

24. Mettler, T.; Rohner, P. Situational maturity models as instrumental artifacts for organizational design. In Proceedings of the 4th International Conference on Design Science Research in Information Systems and Technology, Philadelphia, PA, USA, 7-8 May 2009; p. 22.

25. Jonker, C.M.; Popova, V.; Sharpanskykh, A.; Treur, J.; Yolum, P. Formal framework to support organizational design. Knowl. Based Syst. 2012, 31, 89-105. [CrossRef]

26. Mobach, M. A Critical Systems Perspective on the Design of Organizational Space. Syst. Res. Behav. Sci. Off. J. Int. Fed. Syst. Res. 2007, 24, 69-90. [CrossRef]

27. International Council on Systems Engineering. What is Systems Engineering? INCOSE. Available online: https://www.incose.org/systems-engineering (accessed on 30 December 2018).

28. NASA Systems Engineering Handbook. National Aeronautics and Space Administration, NASA SP-2016-6105 Rev 2. 2016. Available online: https://www.nasa.gov/sites/default/files/atoms/files/nasa_ systems_engineering_handbook_0.pdf (accessed on 8 August 2019).

29. Blanchard, S.; Fabrycky, W. Systems Engineering and Analysis, 5th ed.; Prentice Hall: Upper Saddle River, NJ, USA, 2011; ISBN 978-0-13-221735-.

30. Harris, G. Lifecycle Engineering Lecture - INSY 7710, Auburn University, January 2018.

31. Cloutier, R.; Sauser, B.; Bone, M.; Taylor, A. Transitioning Systems Thinking to Model-Based Systems Engineering: Systemigrams to SysML Models. IEEE Trans. Syst. Man Cybern. Syst. 2015, 45, 662-674. [CrossRef]

32. Department of the Army, Army Contracting Command. Request for Information (RFI) Digital Manufacturing and Design Innovation-Proposed Institute. 9 May 2013. Available online: https://www.fbo.gov/?s= opportunity\&mode $=$ form $\&$ id $=05872 \mathrm{~b} 72 \mathrm{e} 4 \mathrm{a} 220382 \mathrm{fb} 6 \mathrm{de} 25 \mathrm{e} 1789 \mathrm{db} 6 \& \mathrm{tab}=\mathrm{core} \&$ _cview $=0$ (accessed on 8 August 2019).

33. Sisti, F.; DeWitt, T. Linking Leadership and Technical Execution in Unprecedented Systems-of Systems Acquisitions. J. Integr. Syst. Des. Process Sci. 2007, 11, 78.

(C) 2019 by the authors. Licensee MDPI, Basel, Switzerland. This article is an open access article distributed under the terms and conditions of the Creative Commons Attribution (CC BY) license (http://creativecommons.org/licenses/by/4.0/). 